\title{
Juan J. Linz in memoriam
}

Con el fallecimiento del profesor Juan José Linz se marcha una figura señera de las ciencias sociales cuyo legado intelectual es inmenso: siete volúmenes de obras escogidas (se han quedado algunas sin publicar en castellano), docenas y docenas de alumnos y colaboradores en los cinco continentes (65 tesis doctorales dirigidas), y multitud de reflexiones y hallazgos útiles que, en algunos casos, han permitido a las ciencias sociales avanzar por derroteros nuevos, como su categoría de regímenes autoritarios o la pregunta sobre identidades múltiples tan usada en España. Su obra es variada, intensa, amplia, producto de la investigación y reflexión de décadas dedicadas a analizar problemas relevantes de las sociedades modernas: la democracia, los fascismos, el estado, los nacionalismos, los regímenes políticos, los intelectuales, el empresariado, la transición a la democracia, las élites políticas. Como trasfondo siempre estaba la democracia (y sus actores) como escenario deseable para el mundo moderno. El lector interesado que desee aproximarse a la obra de Linz sin prejuicios ideológicos puede hacerlo leyendo sus trabajos en castellano compilados como Obras escogidas por José Ramón Montero y Jeff Miley y editados por el Centro de Estudios Políticos y Constitucionales. Allí encontrarán también el texto actualizado de Houchang Chehabi "Una bibliografía de Juan J. Linz», donde se da cuenta de sus trabajos (útilmente clasificados por temas) y de los que tratan sobre Juan Linz (entrevistas, análisis, notas biográficas, volúmenes conmemorativos). En esta nota no entraré en el tratamiento de su obra más que en algunos aspectos. Quiero arrojar luz sobre algunas facetas menos conocidas de Linz como profesor y como investigador.

\section{El profesor}

Como profesor, Juan Linz era un docente extraordinario por su erudición y conocimientos de primera mano. Sus clases tendían a ser largas, muchas veces sobrepasando el límite establecido pero manteniendo a la audiencia interesada 
e intrigada por los matices y los excursus tan notables en sus clases como en sus publicaciones. Algunos de ellos bien merecían un curso monográfico en sí mismos, como las relaciones entre religión, nacionalismos y política que abordaba tanto en sus cursos sobre nacionalismos en perspectiva comparada como en los de religión y política que enseñó en Yale. Sus alumnos recordarán multitud de anécdotas en sus clases, generalmente relacionadas con los ducados que fumaba (cuando se podía fumar en las aulas), el bolso de libros que siempre llevaba consigo a las clases (y de donde sacaba las muchas citas con las que ilustraba sus conferencias) o su aparente impasividad cuando se apagaba la luz del aula y seguía disertando sobre un tema como si no hubiera pasado nada o como cuando salía humo de una papelera (por el Ducados mal apagado) y seguía hablando sobre algún asunto del curso como si no fuera con él.

Pero más allá de su labor docente, donde realmente marcaba la diferencia era como director de tesis. Sus doctorandos trabajaron en los temas más variados. El último, Juli Minoves, sobre las monarquías, asunto sobre el que Linz defendía que algo debían tener de elemento equilibrador cuando las monarquías parlamentarias se comportaron de manera diferente en el período de entreguerras aportando estabilidad a la democracia. El «casi» último es Ramiro Cibrián, cuya tesis sobre el País Vasco verá la luz en la primavera de 2014. Les precedieron más de sesenta doctores que pasaron por experiencias similares. Ser alumno de Juan Linz significaba dejarse las pestañas trabajando, leyendo, escribiendo y reescribiendo, viajando, buscando datos y, sobre todo, conversando. Una tesis con Linz era una conversación continua salpicada de cotidianidad, estímulo intelectual y el cariñoso afecto y preocupación de Rocío Terán, su esposa y colaboradora en tantas aventuras intelectuales y encargada de una logística sin la que Juan Linz no habría llegado donde llegó. Rocío, autora de un magnífico libro sobre la historia sociopolítica del tulipán y de varios cuentos infantiles sobre los mifenses, es la afamada responsable de las hearty meals que disfrutaron varios miembros de una generación de científicos sociales brillantes que formaban la escuela invisible de Linz (desde Seymour Martin Lipset hasta Al Stepan pasando por Daniel Bell y Reinhard Bendix, entre otros). También sus alumnos mitigaban las largas horas de trabajo en el comedor-bibliotecaoficina-sala de estar con las atenciones extraacadémicas (no solo gastronómicas) de una pareja acogedora tanto intelectual como humanamente.

Trabajar con Linz en una tesis doctoral era duro. El estudiante iba con uno o dos capítulos de su tesis o con un planteamiento inicial, y Juan Linz casi siempre ponía la luz sobre puntos oscuros, lagunas, lanzaba ideas, paradojas, daba referencias. Durante la conversación sacaba libros de su biblioteca y los ponía a su lado indicando que ese era un buen libro para la tesis. El momento culminante de esta experiencia llegaba cuando el doctorando tenía que marcharse. Inevitablemente, no podía hacerlo sin la ayuda de una bolsa generosa donde poner todos los libros que el profesor había ido acumulando durante la conversación como apoyos para que el estudiante desarrollara su trabajo. Para muchos era deprimente. Los borradores quedaban destrozados y había que comenzar a trabajar de nuevo. Pero llegaba el momento de leer los textos 
recomendados y se comenzaban a abrir ventanas al mundo que arrojaban luz nueva sobre el fenómeno que se quería estudiar. Para muchos de sus alumnos, esas lecturas se convertían en muletas con las que caminaban hasta concluir la tesis. Para muchos otros, esos textos recomendados, junto a las ideas del profesor, fueron pilares de conocimiento sobre los que se asentaron desarrollos profesionales futuros.

Juan Linz revisaba cada página que escribían sus alumnos. Línea a línea. Sugería mejoras, criticaba ideas erradas, señalaba problemas, corregía errores ortográficos, gramaticales o incluso tipográficos. Lo solía hacer en su casa de Handem, pero no era raro que lo hiciera también en un aeropuerto donde se citaba con un estudiante camino de otro país, o en un bar cerca de cualquier sitio donde estuviera trabajando. En muchas ocasiones era puntilloso y exigente, aunque siempre comprensivo con las circunstancias de cada cual y respetuoso con el trabajo de los demás. Tuve la oportunidad de escuchar en una ocasión el motivo de su exigencia para con los estudiantes. Más o menos era este: ahora puedo enseñarles lo que sé. Cuando son doctores, ya se convierten en colegas, dejan de ser estudiantes, y ahí ya el papel es otro.

Lo bueno de Juan Linz para sus estudiantes es que predicaba con el ejemplo. Exigía a sus alumnos, tenían que trabajar mucho, pero él también. Era un trabajador incansable capaz de estar hasta altas horas de la madrugada dictando a su grabadora (difícilmente escribía a máquina y el ordenador no lo usó), editando sus trabajos o escribiendo notas manuscritas que usaría al día siguiente (su escritorio era una vorágine de papeles y libros). Su máxima era la edición: un trabajo no estaba bien hecho si no se había revisado y corregido varias veces o, como solía decir, si no se le había dado "varias pasaditas». Y ahí es donde entra la escuela invisible y la profesión como fuente de ideas y mejoras. Lo expresaba de esta manera: «Los trabajos de investigación no son fáciles de escribir. Cada cosa pasa por numerosos borradores. Escribes un primer borrador, lo discutes con tus colaboradores, lo enseñas a tus colegas, lo presentas en una reunión para pedir ideas nuevas, sigues trabajando en él [...] Requiere tiempo y trabajo. Necesitas dedicarle largas horas: escribiendo, pensando, sentado frente al ordenador. [...] Investigar significa esforzarse. Significa que, durante las vacaciones, en lugar de ir a la playa, haces investigación. [...] El trabajo de un investigador, el trabajo de un académico a veces se sobrepone al de las vacaciones; a veces te toma los fines de semana [... N Nada se hace a menos que le dediques tiempo y trabajo. Pero es divertido» (p. 471). ${ }^{1}$ Por un lado, Juan Linz entendía que el esfuerzo y la dedicación eran características obligatorias en todo académico porque presuponía que todo académico está movido por la pasión investigadora, por la libido sciendi. Por otro lado, era consciente de que la construcción del conocimiento (la investigación bien hecha) es el resul-

1. Todas las citas de Juan Linz en este trabajo provienen de una entrevista compendiada en Coller, Xavier), «University, knowledge and society: A conversation with Juan J. Linz», en Gabriel Castro y Jesús M. de Miguel (eds.), Spain in America. The first decade of Prince of Asturias Chair at Georgetown University (Madrid: Fundación Endesa, 2010), p. 461-76. 
tado del esfuerzo individual y colectivo. De ahí que su obra estuviera siempre sometida al juicio de la profesión en multitud de congresos y seminarios y que animara a sus alumnos a que hicieran lo mismo.

Pero su tarea como director de tesis no concluía con la defensa. Juan Linz ejercía de mentor para muchos de sus alumnos. Escribió cientos de cartas de recomendación para las instituciones que pedían referencias sobre tal o cual postulante a un puesto, beca o premio. Facilitaba contactos para iniciar nuevas investigaciones o avalaba con sus cartas introductorias el trabajo que hacía algún colega o estudiante para que pudiera obtener acceso a datos o informaciones útiles. No solo ejerció de mentor para sus alumnos. También muchos colegas de diferentes países se beneficiaron de su ayuda intelectual, especialmente los españoles, a quienes siempre recomendaba salir al extranjero a formarse bien en centros de prestigio y a intercambiar ideas: «Es importante para los académicos españoles que vengan a universidades de prestigio y que interactúen con sus homólogos estadounidenses. Y para los estudiantes de doctorado es importante porque entran en una disciplina académica, una manera de hacer las cosas. Se toman cursos en el departamento, pero el alumno tiene la oportunidad de tomar cursos en otros sitios como antropología o psicología, por ejemplo. Se puede ampliar la perspectiva de una disciplina sin estar atado a un programa específico. Y este creo que ha sido el problema en Europa, particularmente en el modelo español y quizás en el francés. Un contacto más estrecho con otros académicos y con un modelo académico diferente del español, o incluso del europeo, e implicarse con otros colegas que están interesados en otras cosas, otros países, amplía el horizonte y la perspectiva comparada [...] Tan pronto como sales fuera e intercambias ideas con otros estudiantes que tienen un interés en otros países, entonces eres capaz de ver las cosas de manera diferente» (p. 474-5).

\section{El investigador}

Como investigador, Juan Linz era un profesional del matiz y de la perspectiva caleidoscópica. Ningún asunto que investigaba estaba completo hasta que no había agotado el análisis de las dimensiones múltiples que recorrían el fenómeno que le interesaba. Ello era así porque adoptaba la verstehen weberiana como método de aproximación a la realidad para explicarla: intentaba siempre ponerse en el lugar del actor social para entender (y así poder explicar) su curso de acción, sus decisiones, ya fuera un presidente del gobierno, una comisión constitucional, un empresario o ciudadanos.

El punto de partida de sus trabajos era siempre la curiosidad y la relevancia: curiosidad por algún problema, generalmente ocasionado por su experiencia propia (el caso de España estaba casi siempre en el trasfondo de sus trabajos) y relevancia determinada por la importancia del problema para el funcionamiento de una sociedad y de su traslación a otras sociedades. Así, su preocupación por el parlamentarismo frente al presidencialismo no hace sino poner de manifiesto el interés por determinar bajo qué condiciones puede triunfar 
un tipo de régimen democrático u otro y, además, cuáles son las consecuencias diferentes de uno y de otro. Al final de sus días, él y su alter ego Al Stepan seguían insistiendo a los estadounidenses que la paralización del gobierno es posible por el carácter presidencialista de su democracia. Inevitablemente, su condición de europeo, español, residente en los Estados Unidos y conocedor directo de los regímenes latinoamericanos le permitió reflexionar sobre este asunto con informaciones de primera mano.

Su importante contribución al estudio de los regímenes políticos con la creación de la categoría de "regímenes autoritarios» también tiene su origen en la curiosidad y la necesidad de explorar campos nuevos. Está claro que Linz estaba insatisfecho con las tipologías al uso de los regímenes políticos. Pero esa insatisfacción no provenía de su interés por justificar el régimen de Franco, tal como inexplicablemente le atribuyen todavía algunos comentaristas con poco rigor, ignorando las propias explicaciones de Linz y ejecutando ataques ad hominem en lugar de presentar evidencias que refuten la contribución de Linz. La insatisfacción provenía de su propia experiencia desde dentro, puesto que se había dado cuenta de los matices que hacían diferente un régimen totalitario de uno que él denominó justificadamente «autoritario». Al romper la clasificación de regímenes políticos al uso, permitió avanzar en la exploración de otros casos similares al español y, sobre todo, permitió abonar el terreno para entender por qué las democracias pueden ser distintas si parten de un régimen autoritario (caso de España o Portugal, por ejemplo) o de uno totalitario (como en el caso de una buena parte de países de los antiguos países del Este), algo que ilustró convenientemente con Al Stepan en su conocido trabajo Problems of Democratic Transition and Consolidation. Southern Europe, South America, and Post-Communist Europe.

Su máxima era la curiosidad, relevancia y contacto directo con la realidad. Así lo exponía en una entrevista: «El punto de partida es la curiosidad: algo te intriga, hay algo que quieres explicar e intentas comenzar al menos describiéndolo [...] La curiosidad te lleva a comparar, a comprender. El primer paso es describir. Lo primero que necesitas es encontrar qué hay ahí fuera, en la realidad. Eso es por lo que creo que el método de conocer antes lo que se va a investigar y las relaciones que se establecerán entre variables es bastante dudoso. ¡La verdad es que no puedes saber qué variables serán significativas! Las descubres en el proceso de describir la realidad. [...] La clave está en mezclarse con la realidad y tratar de comprenderla preguntando a la gente, poniéndote en su posición. Primero tienes que comprender y luego intentar construir una explicación estableciendo relaciones, comparando, pensando sobre por qué las cosas son como son. Esto es el primer paso. Implica ganar familiaridad con el problema usando todos los datos que puedas obtener a través de la observación personal [...], conversaciones con gente, entrevistas sistemáticas o no, absorbiendo la atmósfera. Tienes que estar ahí, ver cosas. También tienes que realizar observación participante, encuestas, datos estadísticos, censos. Este es el enfoque clásico de la investigación en las ciencias sociales que yo he adoptado. He usado encuestas, estadísticas, censos, observa- 
ción participante. He usado cualquier cosa que me pudiera ayudar a conocer o entender algo mejor» (p. 470).

Sus investigaciones eran el producto de un trabajo artesanal. Ahí seguía la recomendación recogida en La imaginación sociológica de Wright Mills, compañero suyo de departamento en Columbia aunque no tuvieran intercambios intelectuales. Linz se intentaba mezclar con la realidad que investigaba ya fuera directamente (sus anécdotas sobre observaciones, conversaciones o entrevistas eran innumerables) o de manera indirecta, a través de sus colaboradores cuando la salud ya le fallaba. Y de ese contacto directo emergían muchas de sus explicaciones a fenómenos relevantes. No era investigador de despacho, aunque pasara horas y horas sentado escribiendo o dictando a su grabadora.

Juan Linz era transdisciplinar. Lo fue en su formación (se licenció en derecho y se doctoró en sociología) y también en sus investigaciones. Y su recomendación para los estudiantes que querían trabajar con él era la de no encasquetarse en un nicho académico o disciplinar, sino tener amplitud de miras, aceptar influencias diversas, usar también una variedad de teorías que fueran útiles para explicar los fenómenos de interés. En este sentido, también predicó con el ejemplo. Sus trabajos son leídos y usados por profesionales de la historia, sociología, ciencia política. Él mismo pertenecía a los departamentos de Sociología y Ciencia Política de la Universidad de Yale y mantenía contactos intelectuales con expertos en derecho (por ejemplo, constitucionalistas) o en economía. Fue también cofundador del comité de sociología política que comparte la ISA y la IPSA. En consecuencia, no es de extrañar que todos sus trabajos tengan dimensiones múltiples en las que siempre destaca la histórica. En más de una ocasión se le oyó decir (y dejó escrito) que le hubiera gustado ser historiador. No concebía la investigación en las ciencias sociales sin la perspectiva histórica, algo que a menudo olvidamos los profesionales más jóvenes.

Ha fallecido uno de esos científicos sociales a la vieja usanza de los que cada vez quedan menos: un humanista preocupado por los grandes problemas de la sociedad, un profesor excelente, un investigador infatigable, un ser humano excepcional. 